\title{
CAMPUS VIRTUAL DE SAÚDE PÚBLICA: AMPLIANDO O ACESSO AO CONHECIMENTO E FORMAÇÃO EM SAÚDE PÚBLICA
}

Virtual Campus of Public Health: Expanding Access to Knowledge and Training in Public Health Ana Cristina da Matta Furniel'; Rosane Mendes da Silva²

Resumo O Campus Virtual de Saúde Pública CVSP/OPAS é uma estratégia de cooperação técnica no campo de educação em saúde, entendendo conhecimento como um bem público. Rede formada por 12 países que compartilham cursos, recursos e aulas virtuais. Atualmente, abriga 2.050 recursos compartilhados em acesso aberto, cursos, ferramentas de aprendizagem e proposta de integração com redes como UNA-SUS.

Palavras-chave: Gestão do Conhecimento, Educação a Distância, Tecnologias da Informação e Comunicação, Formação em Saúde, Educação Permanente.

Abstract The Virtual Campus of Public Health CVSP/PAHO is a strategy for technical cooperation in health education that understands knowledge as a public welfare. This network consists of 12 countries that share courses, resources and virtual classes. Currently, there are 2050 shared resources in open access, courses and learning tools and a proposal to integrate with other networks including UNA-SUS.

Keywords: Knowledge Management, e-Learning, Information Technology and Communication, Education in Health, Permanent Education.

1.E-mail: afurniel@gmail.com. Gerente de Projetos da Vice Presidência de Ensino, Informação e Comunicação da FIOCRUZ. Coordenadora do Nodo Brasil do Campus Virtual de Saúde Pública CVSP/OPAS. - Mestre em Relações Internacionais; 2. Tecnologista em Saúde Pública - Mestre em Saúde Pública. Recebido em 13/04/2014. Aceito, após revisão, em 10/06/2014. 


\section{Introdução}

O Campus Virtual de Saúde Pública (CVSP) é um espaço para desenvolver cooperação interdisciplinar no campo de formação em saúde pública, uma rede de instituições que compartilham cursos, recursos educacionais e aulas virtuais. Além disso, por meio do projeto Clínica Virtual Docente (CVD) visa reforçar as competências das equipes de saúde da família em áreas indígenas e de difícil acesso nas regiões das Américas adotando um modelo que integra ferramentas para fins de ensino e serviços de telemedicina'.

O CVSP tem como objetivo fortalecer a formação profissional em saúde pública, através do uso intensivo de tecnologias de informação e comunicação (TICs). Um espaço de aprendizagem em rede, resultado de uma parceria entre a Organização Panamericana de Saúde (OPAS) e 12 países da região das Américas (Brasil, Argentina, Chile, México, Colômbia, Costa Rica, Cuba, Equador, Paraguai, Peru, Porto Rico e Uruguai)².

Os recursos educacionais das instituições parceiras dos países da rede são compartilhados em repositórios digitais interoperáveis ${ }^{3,4}$. Com isso, o CVSP disponibiliza aproximadamente 6.000 recursos em acesso aberto, formando uma rede, denominada Rede REA/OER.

\section{Relato da Experiência}

O Campus Virtual de Saúde Pública (CVSP/Brasil) constitui-se um nó da rede baseado num modelo de gestão descentralizada. Lançado em 2003, é liderado pela Fundação Oswaldo Cruz (Fiocruz), através da Vice-presidência de ensino, informação e comunicação. Estabeleceu cooperação técnica com a Rede de Escolas e Centros Formadores em Saúde Pública, composta por 44 instituições e a Universidade Aberta do SUS (UNA-SUS) do Ministério da Saúde (MS), com 36 universidades.
O CVSP/Brasil compartilha os objetivos do CVSP/ Regional, tendo como principais serviços: um ambiente virtual de aprendizagem, na plataforma MOODLE5 repositório de recursos educacionais e um portal agregador de informações da rede.

As ofertas formativas do CVSP são constituídas pela integração das diversas instituições que oferecem cursos e recursos que respondam aos padrões adotados, bem como pelo uso comum de ferramentas tecnológicas para intercâmbio de informações nas diferentes redes parceiras, especialmente com a Rede da UNA-SUS e Rede de Escolas de Saúde Pública.

\section{Discussão}

Há de se reconhecer que a incorporação das TIC é uma das diretrizes para a formação para o SUS e para o sistema de C\&T no Brasil. Para isso, é importante apoiar e dar condições para a articulação de uma Rede de tecnologia, informação, comunicação e educação em saúde, integrando os processos informativos dos formativos.

A aprendizagem é concebida como o processo de resolução de problemas, capacidades ou a revisão de critérios e modelos já existentes. Supõe uma mudança na lógica de cursos de transmissão vertical, centradas no fornecimento de informações atualizadas sobre um determinado assunto e incorpora um enfoque com base na identificação de problemas e reflexões de práticas de trabalho, o que abre caminho para a construção de novos conhecimentos e alternativas de ação $0^{6,7}$.

Atualmente, a rede do CVSP/Brasil possui mais de 2.050 recursos educacionais compartilhados em acesso aberto.

O CVSP/Brasil foi selecionado pelo portal da Rede de Recursos Educacionais Abertos, entre as iniciativas que se destacam no apoio e divulgação de Recursos Educacionais Abertos (REA) no país, especialmente aquelas com política de licenciamento aberto unificada/compatíveis com a definição de REA adotada pela Rede REA no Brasil. 


\section{Comentários Finais}

A iniciativa do CVSP pode ser considerada exitosa pela adoção de uma estratégia composta pelos seguintes modelos de referência: governança, Educação, Tecnológico, Financeiro, avaliação e plano de comunicação. Suas ações são realizadas numa abordagem em rede para atender às necessidades dos sistemas de saúde, associando ao mesmo tempo diretrizes do Sistema Único de Saúde - SUS e de Ciência e Tecnologia.

Um dos mais importantes desafios para que se atenda a essas orientações consiste na escala de formação, que exige cada vez mais o desenvolvimento de tecnologias e metodologias de ensino e comunicação (plataformas de EAD, telessaúde, produção e difusão de recursos educacionais).

Os avanços alcançados pela Fiocruz (coordenação do Nodo-Brasil) são reconhecidos, mas há necessidade de maior integração das ações educacionais realizadas pelas diferentes unidades, favorecendo seu alinhamento às necessidades do SUS 8 .

Dessa forma, como proposta de ampliação do projeto e da rede, o Campus Virtual Fiocruz será um espaço virtual que permitirá agregar e integrar iniciativas das redes participantes e unidades Fiocruz.
Referências

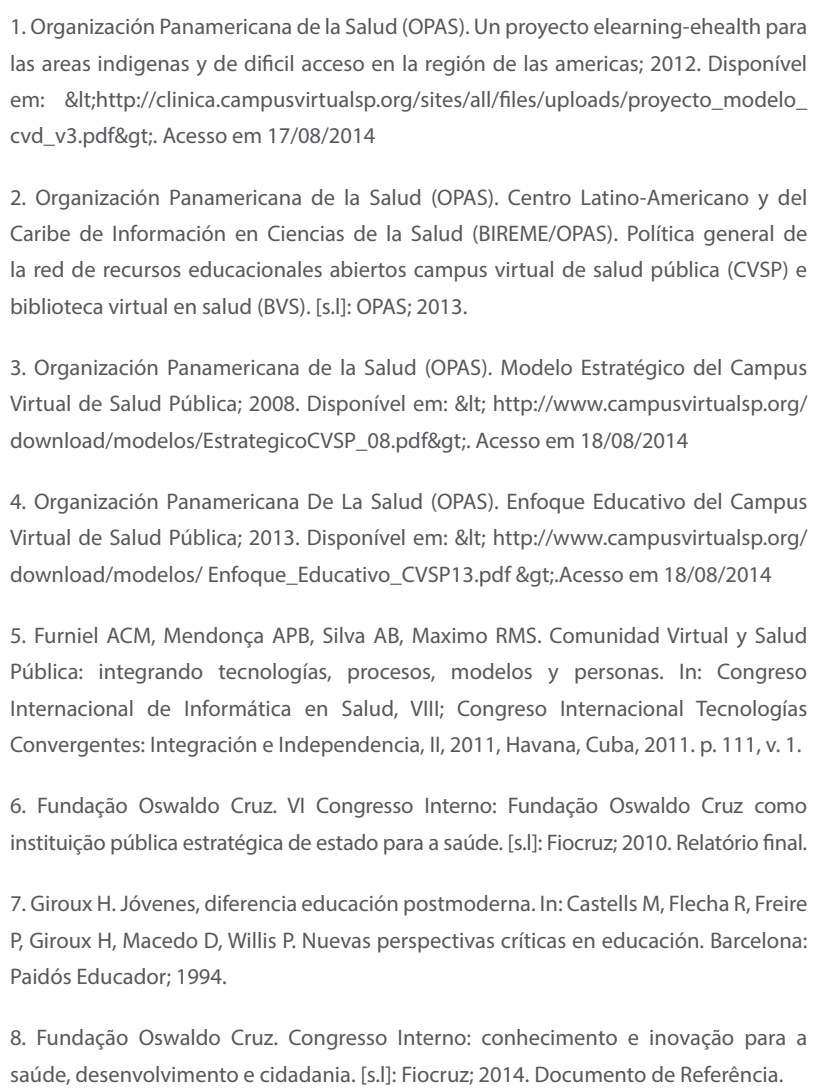

